\title{
An experiential approach to research in planning
}

\section{Thomas Straatemeier, Luca Bertolini, Marco te Brömmelstroet}

Amsterdam Institute for Social Science Research, University of Amsterdam, Nieuwe Prinsengracht 130, 1018 VZ Amsterdam, The Netherlands; e-mail: t.straatemeier@uva.nl,bertolini@uva.nl, M.C.G.tebrommelstroet@uva.nl

\section{Perry Hoetjes}

Stadgenoot, Sarphatistraat 410, PO Box 9252, 1006 AG Amsterdam, The Netherlands; e-mail: PHoetjes@stadgenoot.nl

Received 26 September 2008; in revised form 17 June 2009; published online 17 May 2010

\begin{abstract}
Most planning research seeks to understand how current planning practices influence (and are influenced by) the processes and institutional contexts of decision making and the transformation of spaces. Typically, analytical methods borrowed from other social sciences are employed for this purpose. However, if one wants to know how new planning practices can be generated, a different research approach seems to be needed. Relevant innovations do not originate in an academic vacuum, but have to be developed in coproduction with intended users and in the context of their intended use. Only then can a reciprocal learning process between research and practice be activated in which original hypotheses about possible planning innovations are developed through iterative testing, reflection, and adaptation. In our opinion, carrying out research into possible planning innovations thus requires a different type of research methodology from the one typically applied. Because of its static nature, a traditional comparative case-study analysis - as often used in planning research - does not allow for such an iterative, evolutionary process. In this paper we propose a new methodology, which we have labelled 'experiential case-study analysis'. In this approach each case study provides learning experiences that fuel theory building, but also serve as input for the next case study. We have used this approach to develop and test different planning innovations in three case studies in the field of transport and urban planning in The Netherlands.
\end{abstract}

\section{Research in planning as a design science}

Planning is not just concerned with understanding the world, but also, and fundamentally, with changing it. Academic research in planning should reflect this fact, which sets it apart from research in most natural and social sciences. These are primarily concerned with comprehending phenomena, and only secondarily and indirectly with influencing them (if at all). In this respect, research in planning appears closer to research in disciplines such as management, law, engineering, or medicine, which, in spite of great differences in their domains of application, are all primarily concerned with how to affect (rather than just describe and explain) their objects of study. Much academic research in planning does not seem, however, to acknowledge this. In this paper, we will argue why we believe so, and propose an approach to academic research in planning that might better reflect its primary concern with changing, rather than just understanding, planning practices. However, first we need to elaborate further on the notion of an orientation of research towards understanding as opposed to an orientation towards change, and on the implications of the difference.

In order to distinguish it from the 'explanatory science' type of research that all research tends to be identified and compared with, Van Aken (2004; 2005) calls change-oriented research 'design science' [inspired by Simon (1969); see also Schön (1983)]. What design sciences have in common is the awareness that "understanding a problem is only halfway to solving it. The second step is to develop and test 
(alternative) solutions" (Van Aken, 2004, page 220). Thus, explanatory and design sciences have different missions. The core mission of explanatory sciences is to describe, explain, and possibly predict observable phenomena within their field (natural or social). An explanandum, or 'something to explain', is their object (as in the questions 'How did different species come to be?' and 'Why is there poverty?'). Descriptions, explanations, and predictions are their typical products. Depending on the object of study (natural or social) such descriptions, explanations, and predictions will, quite fundamentally, be more or less value and context free [as, for instance, is extensively discussed by Flyvbjerg (2001)]. Whatever the case, some sort of causal model will remain the central concern.

Design sciences have a quite different core mission. The focus is not primarily to develop a causal model, but rather to develop knowledge for the design and realisation of artefacts (as, for instance, in engineering or architecture), or for the improvement of the performance of existing entities (as, for instance, in medicine or management). A mutandum of 'something to change', is their object (as in the questions 'How to cure AIDS?' or 'How to improve the performance of a governmental organisation?'). The typical products of design sciences are prescriptions ('If you want to achieve $\mathrm{Y}$ in situation $\mathrm{Z}$, then something like action $\mathrm{X}$ will help'). They are prescriptions that are tested in practice and grounded in scientific knowledge. Central design-science research questions are 'What works?' and 'Why does it work?', or more precisely: 'Through which mechanism does a certain intervention impact on a certain context to determine a certain outcome?' (Van Aken, 2004, based on Pawson and Tilley, 1997).

As a discipline oriented towards change, planning research should also be expected to follow this model of 'design sciences'. However, and certainly as far as academic research in planning is concerned, it mostly seems to follow the mode of 'explanatory sciences'. It might still ask questions such as 'what works?' and 'why does it work?' but, crucially, it does not seem to care to submit its findings to the full experiential cycle of actually implementing interventions and reflecting on their outcomes. ${ }^{(1)}$

To a large extent the idea of engaging with practice is already well known as 'action research'. Indeed, action research has some essential correspondences with design sciences, as demonstrated, for example, by Argyris and Schön (1989). Both design sciences and action research are focused on finding solutions in close cooperation with practitioners, and both types of research take place through iterative action-reflection cycles. Like design science, 'good' action research requires not only practical results in the specific cases of intervention, but also a certain degree of generalisation (Eden and Huxham, 1996). However, at least partly owing to the origins of action research as a method of facilitating social change and empowering 'the client', often the emphasis is more on 'action' than 'research'. Hence, transferring the knowledge obtained from the

${ }^{(1)} \mathrm{A}$ review of articles published recently in some of the most practice-oriented academic planning journals seems to confirm this pattern. Four journals were scanned for contributions featuring (de facto) grounded and tested technological prescriptions: the Journal of the American Planning Association, Planning Practice and Research, Planning Theory and Practice, and the Journal of Planning Education and Research. These journals have the explicit aim to publish research which is relevant for practitioners, and to bring together practice and academia. Scanning recent issues of these journals appears to reveal that truly tested and grounded prescriptions are a mere exception. The majority of contributions (over $85 \%$ of the scanned articles) consist of explanatory analyses of physical and social phenomena, policy analyses, or theoretical contributions. Most of these contributions result in recommendations for policy or further research. This type of research more or less merges into a category of articles that can be labelled as featuring prescriptions that are grounded in theory, but have not been tested in practice. In the end, there was arguably only one article, out of ninety-nine articles scanned, that engaged in the full experiential reflective cycle, resulting in the reporting of a grounded prescription that was actually used and tested in a practical case (Cervero, 2006). 
context of action research to other contexts tends to be problematic (Argyris and Schön, 1989; Baskerville and Wood-Harper, 1996; Eden and Huxham, 1996; Stringer, 1999; Van Aken, 2004). The design-science approach on the other hand, is intended explicitly to generate grounded and tested prescriptions to be of use in other contexts as well. The basic aims of design science are also central to the work of Friend and his fellow researchers, and particularly to their 'theory of strategic choice' (Friend and Hickling, 1987). The theory of strategic choice can indeed be seen as a grounded and tested prescription as defined above. There is, however, a difference in focus with the approach put forward in this paper. The strategic-choice approach is essentially, as also noted by Needham (2004), a methodology for planning practice, while the primary aim of this paper is to provide a methodology for planning research.

First we give a further elaboration on the notion of the experiential cycle, its roots in American pragmatism, and its application to professional education, most importantly in the work of Schön (1983). Second, we propose our elaboration of the experiential cycle as a way of structuring planning research and articulating its interaction with planning practice. Third, we illustrate and reflect on its workings through three examples of research in which we are presently engaged. Finally, we elaborate on some broader implications of our argument for academic research in planning.

\section{Research as learning}

The relationship between knowledge and experience was a core concern of American pragmatism. Central to American pragmatism in general and to the work of Dewey $(1960 ; 1964)$ in particular is the notion that practical knowledge can only be generated within actual experience. According to Dewey, human practices are based on more dimensions of 'knowing' than on the merely cognitive type of knowledge experts typically contribute. He pointed to knowledge dimensions such as 'reflection', 'value', 'experience', and 'emotions'. Dewey further ascertained that human knowledge is always incomplete and imperfect, even in its richest forms. The knowledge of acting subjects is thus, and by definition, far less complex than the practices they are engaged in. As a result, one cannot cope with the complexities of practice just from an outside, spectator position. One can only learn the real meaning and value of knowledge by trying and probing it in action.

This key pragmatist notion has been articulated further and made operational in the field of education by Kolb and Fry (1975) in the theories and methods of 'experiential learning'. Experiential learning unfolds through an iterative sequence of interlinked activities, with a continuous shift between reflection and action, the one nurturing the other. In this learning cycle, the observation of and reflection on
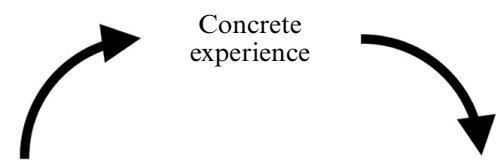

Testing in new situations

Observation and reflection

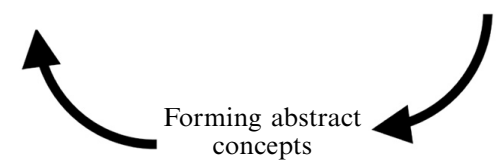

Figure 1. The experiential learning cycle (adapted from Kolb and Fry, 1975). 
concrete experience leads to the forming of abstract concepts, which are then tested in new situations, eventually resulting in the adaptation of existing practices (that is, concrete experience), in a continuous flow (figure 1).

The experiential learning cycle can also provide a useful framework to characterise planning research, planning practice, and their (potential) relationship. The four activities are, of course, already present in current planning research and practice. However, and this is the core of our argument, they are often not linked, at least not systematically or directly. Our contention is that a more direct and systematic link between these different activities (and the people and organisations behind them) would much improve learning processes and thus knowledge development in planning research and practice. This requires change on both sides. Researchers need to engage more in practice (in 'concrete experience') and practitioners need to engage more in research (in 'forming abstract concepts'). As, in our highly specialised work, it is difficult to expect an individual or even a single organisation to be equally capable in all these activities, practitioners and researchers (and the respective organisations) have to engage more with each other: the former providing 'food for thought' the latter 'thought for food'.

This is, of course, a sort of reasoning that has already been made in the planning community, most notably and forcefully by Schön (1983), and it is directly inspired by both his general notion of 'reflective practice' and his specific ideas of the sort of research that can support it (pages 307-325 in particular). We share with Schön the conviction that this is the obvious model for knowledge development in the professions in general and planning in particular. It is a conviction that is also increasingly echoed in other fields and debates, as in the contention that science's 'codified' knowledge and practitioners' 'tacit' knowledge must be intimately combined to achieve innovation [Nonaka and Takeuchi (1995); see also earlier studies by Friedmann (1973); Polanyi (1967)], or that knowledge development in science, technology, and society needs to be integrated if complex societal problems are to be tackled (Gibbons et al, 1994; Nowotny et al, 2001; Thompson Klein et al, 2001). More specifically, we think that the experiential learning cycle could be a useful model for structuring planning research in a way that leads to a more fruitful exchange with planning practice, as introduced in the next section.

\section{Towards an experiential research design}

Using the experiential learning cycle of Kolb and Fry (1975), we have developed a research design for planning research based on a sequential case-study method (see figure 2). The letters refer to the different stages in the learning cycle mentioned in figure 1. Figure 2 shows the different steps in the experiential learning cycle placed between planning research and planning practice. Instead of a dichotomy, we see research in planning and planning practice as two sides of a spectrum. Within this spectrum concrete experience is more embedded in planning practice, whereas forming abstract concepts is more embedded in the world of research. Observation and reflection and testing in new situations are at the interface. Testing in new situations has to be close to planing practice in order to simulate real conditions, but it must also hold the possibility to experiment and fail, which might be problematic in real planning processes. Observations and reflection also relates to both ends of the spectrum. They can only be effective if not only the practitioners but also the researchers have been part of the planning practices they want to reflect upon. At the same time the researchers, as well as the practitioners, are asked to take a step back and reflect critically upon the practices they have been engaged in. 


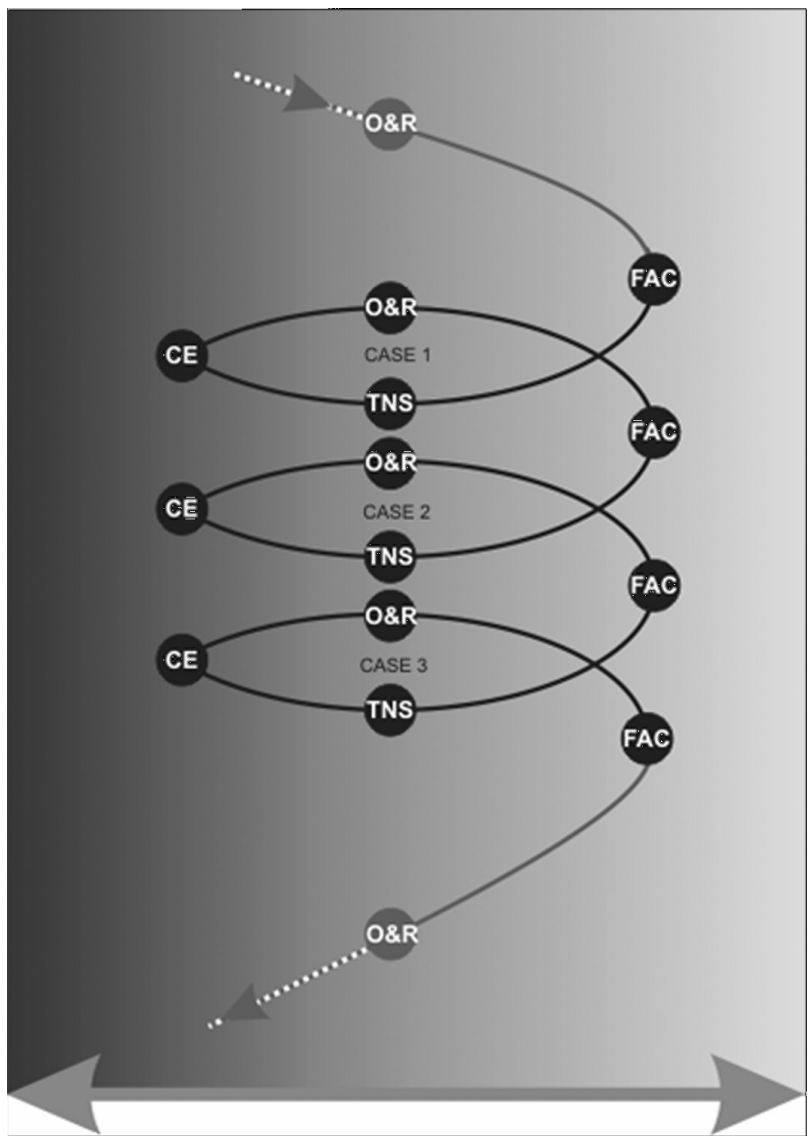

Planning practice

Planning science

Figure 2. Experiential research design. $O \& R=$ observation and reflection; $F A C=$ forming abstract concepts; $\mathrm{TNS}=$ testing in new situations; $\mathrm{CE}=$ concrete experience.

In this approach, each case study provides learning experiences that serve as an input for the next case study, which is why we called it an experiential case-study analysis. The central idea is that research should go through at least a number of cycles. This means that abstract concepts are tested and reflected upon in several subsequent planning practices. Multiple reflections on concrete experiences are needed to understand if adaptations to abstract concepts made after the first test actually lead to better planning innovations. The most important aspect is to gain insight into the underlying mechanisms. Why does a particular planning innovation work, or not work? In order to understand the mechanisms, the researcher has to reflect upon different aspects in each case. What has been the outcome of the experiment? Did it, for example, lead to new and better decisions? And what might be the cause for this? To what extent can the outcomes be linked to the new innovation or the particular planning context in which the intervention was tested? Changing (with the aim of improving) the intervention between cases might shed more light on the mechanisms that cause different outcomes, while at the same time developing sensitivity for differences in context that might influence these same outcomes. Therefore, each research design should consist of multiple cases, so that one can differentiate between casespecific outcomes and innovation-related outcomes. The latter is, of course, just good practice in case-study research (Gerring, 2007; Yin, 2003). However, a fundamental 
difference is that cases are not studied in parallel but rather in series (see figure 2), meaning that hypotheses are allowed to evolve during the course of the process.

In the next sections we introduce three research projects in the field of transport and urban planning in the Netherlands to illustrate how the methodology has been applied. The abbreviations introduced in figure 2 will be used (in brackets) to emphasise the different phases of the learning cycle. Rather than the content of the analysis, it is the process of doing research on the basis of an experiential case-study design that is to serve our argument.

\section{Research I: mediated planning support}

The research described in this section is part of a large scheme of a national government-sponsored research programme called Transumo. Transumo aims to develop innovations in the field of transportation planning. Each research project within Transumo is organised according to a tripartite funding mechanism, ensuring financial commitment and participation of universities, governments, and private stakeholders.

The basis of this research project was the observation that numerous models for land-use and transport integration have been developed in recent years, but that few of these have actually been used in daily planning practice. The goal of the project was to gain more insight into why the developed tools are seldom used and how this could be improved. Interviews with instrument developers and a survey among Dutch planning practitioners [observation and reflection [O\&R)] showed that bottlenecks for these specific models mirrored wider research findings on implementation difficulties of planning support systems (PSS): a lack of transparency, a poor link to the complex planning context, and too focused on technology (for example, Geertman and Stillwell, 2008; Lee, 1994; Vonk et al, 2005). On the basis of further insights from literature on technological innovation, knowledge management, and collective learning, a method was developed to address these bottlenecks [forming abstract concepts (FAC)]. The main hypothesis of this method [coined mediated planning support (MPS)] is that in a structural dialogue between modellers and intended users more useful land-use and transport PSS are developed. This occurs in a stepwise and iterative manner that facilitates reciprocal interchanges between the explicit knowledge that the model produces and the tacit knowledge of the intended users [for further detail, see te Brömmelstroet and Schrijnen (2010)]. In 2006 and 2007, MPS was first applied in the Amsterdam region [testing in new situations (TNS)], where planners and modellers wanted to improve the support for integrated land-use transport strategy development with the municipal transport model (GenMod). In six workshops supervised by the research team the group developed and used a process protocol (three-step policy-design process), discussed, selected, and used relevant information for each step, and used these products to develop integrated land-usetransport strategies (see te Brömmelstroet and Bertolini, 2008). On the basis of observation, individual questionnaires, and surveys filled in by the practitioners, the research team reflected on this first experiment with MPS (O\&R). The planning participants stated that this method of working made existing ideas more explicit and provided stronger support for these ideas in the form of indicators and maps. The modellers perceived the discussion with end-users about the information needed (both before and during the design process) as a crucial element in order to produce a model that is useful for policymakers. The planning steps for which the information was used (an important part of a PSS) was seen as less important and a three-step design protocol was taken for granted in an early stage of the process. 
Main reflections were that the initial setup of the PSS should take up less time, making room for more learning by doing. Furthermore, the focus on MPS should be on collective learning and not on developing an optimal plan. Insight into robust strategies and interdependencies (increasing strategic capacity) are the preferred planning outcomes of such processes. After the case study, the GenMod modellers wrote a guide to support modelling in future strategic-planning exercises. In addition, efforts were made to make the model more accessible to policymakers (for example, by developing faster algorithms and providing desktop versions (concrete experience [CE]).

These observations and experiences led to a revised version of the MPS (FAC), which was used in a second case study, in the city of Breda (TNS). Here, land-use transport planners wanted support to develop integrated strategies for a railway station development project and a spatial plan for its surroundings. In this case, due to a lack of in-house modelling expertise, information delivered by a consultant and the Dutch Railways was used. Here, the MPS methodology was executed in four workshops, with the first one focusing on constructing the complete (but preliminary) PSS, identifying the planning issue, relevant information, and a proposed process framework. The second workshop was used to diverge into two land-use-transport alternatives. In the third workshop the effects of the alternatives were presented and discussed, and from this, the alternatives were refined. In the fourth workshop a list of robust strategies and interdependencies was developed. Reflecting on this case (O\&R) revealed the crucial role of the modeller for the success or failure of the collective learning process. He or she has to be present in all steps to facilitate internalisation and socialisation of the explicit knowledge that the model offers. Also, while MPS was designed for group learning, in reality, keeping a group of planning practitioners together over a period of four workshops is hard, if not impossible, to achieve. In future attempts these dynamics have to be taken into account.

The modellers, especially in the first case study, now have hands-on experience with a user-based participatory process of PSS development. As a result they learned how they should position themselves as intermediaries between their models and the users. Without this hands-on experience such a change of positions is much harder to achieve (Meadows and Robinsons, 2002). They have experienced that this leads to a higher use of their PSS in integrated land-use and transport strategy development. Together with the researchers, they abstracted the lessons learned in a handbook for future planning-support situations.

In this project the researcher organised and chaired the workshops, but the content was provided mainly by the relevant government staff (urban planning problems) and consultants (supporting knowledge and computer models). In the case discussed here, planning practitioners approached the university to start a series of workshops. They appreciated that it created a space for them to reflect on their daily planning work. The link with political decision making was - for the last reason-kept to a minimum.

\section{Research II: joint-accessibility design}

The second research example is also derived from transportation planning, and it is also part of a national government-sponsored tripartite research programme (Habiforum). Integration of transport and land-use planning is seen as a crucial step towards more sustainable mobility patterns (Meyer and Miller, 2001). However, for many reasons, this seems difficult to achieve in practice (Banister, 2005). Interviews with practitioners in the Netherlands already showed that in the early phases of policy design integration is often missing (O\&R). Examining current research in transportation planning, it was hypothesised that the concept of accessibility could be useful to stimulate integration in these early phases of policy design, since accessibility relates 
to both the qualities of the transport system (reflecting the travel time or costs of reaching a destination) and the qualities of the land-use system (reflecting the qualities of potential destinations). Accessibility is a well-known and well-studied concept within scientific literature [for an overview see Bhat et al (2000)] but its use in practice is limited. A framework was developed by the researchers, and was labelled ‘joint-accessibility design' (FAC). This framework aims to help planners use accessibility as a planning concept in practice to support the design of integrated transport and land-use policies. The framework consists of a series of workshops facilitated by the university in which different accessibility maps and indicators are used to support the policy design [for details see Straatemeier and Bertolini (2008)].

The first testing of the framework took place in a policy-design studio set up by the province of South Holland (TNS) in which transport and land-use planners where brought together. The province cofinanced this application of the framework since they saw this as an opportunity to address planning problems regarding future urban development in a new way. The results of the first experiment were set out in two publications which were coauthored by planners from the province, one explaining the methodology of the framework to the practitioners and one showing the results of the accessibility analysis. Some of the participants seemed to continue using accessibility as a conceptual framework for use in their daily planning work (CE), while others did not, indicating that the framework could be improved. Using questionnaires completed by practitioners and interviews to reflect on the first case, several conclusions could be drawn relating to the process of workshops as well as the accessibility analysis (O\&R). First, it turns out that accessibility is a bit like a double-edged sword. Transport and land-use planners are enthusiastic about the concept, but find that the indicator is not always easy to understand, especially for land-use planners. A reason for this could be the fact that in this case the accessibility analysis was largely carried out by the University of Amsterdam. This meant that the practitioners who had to use the accessibility analysis lacked the direct insight into how the results were produced. Second, the first case was not linked directly to a specific planing problem, resulting in the use of societal goals that were not well defined, making it difficult to find suitable indicators. Finally, in this case there was a lack of possibilities to assess changes in the land-use system as a result of different interventions due to a lack of data. This hampered the policy design since insight into options for changing current accessibility conditions was limited. Using the experiences of the first case it was theorised (FAC) that in order to use accessibility as a planning concept, more time has to be dedicated to understanding and learning about the concept, the way accessibility changes as a result of interventions, and the need to adapt and conceptualise accessibility within the context of a particular planning problem. This confirms research by Innes and Booher (2000), which shows that in terms of a learning experience the process of making an indicator is more important than the final indicator itself. Practitioners thus have to learn how to use the concept of accessibility and the researchers have to learn how to make the concept useful to them.

To stimulate this two-way interaction in the following case of Almere, practitioners (instead of university researchers) aided by consultants performed the analysis in order to verify if this enhances the learning process (TNS). During the workshops more time was dedicated to allow planners to understand the measure and to adapt the measure and its visualisation to their needs. Different scenarios were used to shed light on the changes in the transport and land-use system as a result of different interventions. The whole process was linked directly to a well-defined planning problem making it much easier to determine societal goals and link them to useful indicators and interventions. The adaptations to the framework resulted in a much 
better process and analysis using the concept of accessibility. The results were set out in a policy document that was presented to decision makers (CE). Transport and land-use planners involved in the workshops stressed that they will continue to use accessibility as a planning concept in the future and that it increased communication between them. Reflecting on this case (O\&R), one could definitely see the positive impact of the adaptations, but there is also room for further improvement. In both cases, for example, practitioners stated that ideally one should be able to see the effects of changes in accessibility as a result of different interventions in real time in order to support policy-design processes dynamically.

Through testing and reflecting on the use of accessibility indicators in planning, knowledge is produced about how to use these indicators in practice. This knowledge comes in different, and sometimes intangible, forms. It is certainly not limited to how to measure accessibility, but also relates to how to set up a planning process, how to develop a useful indicator that everybody can understand, which planning questions to address with the concept of accessibility, and so on. This type of knowledge can be produced more effectively within an interactive learning environment where both researchers and practitioners are present.

\section{Research III: the urban portfolio}

The third example is from a research project triggered by the idea and experience (CE) that urban developments in the Netherlands are increasingly the result of private initiatives and investments. The local planning department of the municipality of Amsterdam expressed the need for more insight into the market dynamics in the city, particularly in the property market (O\&R). With this notion as a starting point, researchers from the University of Amsterdam and the Amsterdam planning department initiated a joint research project, financed and facilitated by the latter, being the client organisation. The aim was to develop an instrument that provides insight into changing market positions of urban neighbourhoods, in order to support the deliberation of planning strategies. The researchers, in cooperation with the planning department, started hypothesising what type of information about these market dynamics would be useful. This resulted in the concept of what has been labelled the 'urban portfolio': the idea that the city can be seen as a portfolio of neighbourhoods, each with a strategic position that can be mapped. Mapping the neighbourhoods' strategic positions in terms of market dynamics could help in identifying the development opportunities of these neighbourhoods, and the type of public and private intervention strategies needed to achieve particular spatial or social-economic goals [for details see Hoetjes et al (2006)]. At least as important, however, was the issue of how to organise and unlock this type of information in order for it to be useful to practitioners, contributing to the deliberation of planning strategies (FAC).

In order to test the urban-portfolio approach, a number of workshops on the development of specific areas in Amsterdam were organised (TNS) and facilitated by the researchers. The first workshop took place at the level of a single neighbourhood, named Holendrecht. Public and private stakeholders who already had plans for redevelopment, but who still lacked a shared comprehensive strategy, took part. During the workshop, these stakeholders were presented with information about Holendrecht's competitive position within the urban portfolio. Subsequently, the area's position in the portfolio was discussed, followed by a collective analysis of how this position could be influenced and what could be seen as realistic ambitions for the future development of the neighbourhood. The workshop resulted in a shared set of strategic actions, which came as a surprise to many participants since this was more than the group had achieved in two years of discussion. About a month after 
the workshop the group assigned a project leader to start elaborating this strategy (CE). Some of the participants commented that they were pleased to have a truly substantive discussion again, after a period of mostly discussing procedural matters (O\&R). It appeared that this was made possible by presenting new information, which was provided by a supposedly neutral third party (in this case the university in cooperation with the planning department). The approach seemed to benefit from being sufficiently integrated with the existing project group, while at the same time being sufficiently distant from it, leaving the participants room for a discussion that went beyond business as usual (FAC).

In order to see whether these ingredients would make the approach successful elsewhere, two other workshops were organised: a second one focusing on another neighbourhood, and a third one looking at comprehensive strategies on a city scale (TNS). Presenting the same maps and following the same steps, both these workshops resulted in relatively similar learning processes about a neighbourhoods' strategic position. Unlike Holendrecht however, neither of the two workshops led to the same commitment to a new strategy, nor a follow up of any kind (CE). Reflecting on these different outcomes, it appeared that notwithstanding some interesting and useful insights gained through the urban portfolio, there was simply no urgent need for a new, shared strategy for these areas. In addition, there were some comments by participants about the indicators used for mapping the neighbourhood positions, the measurement of which was considered to be insufficiently clear (O\&R).

These observations served as input for theorising about a more general mechanism behind the portfolio approach (FAC). Which part of the results should be seen as casespecific, and which elements would prove to be valid for all cases? It seemed that for the first workshop, the apparent stalemate between stakeholders and the mere fact that there was a substantive discussion in the first place was crucial but limited to this case. The observation that stakeholders need to understand fully the explicit information presented to them, in order to give meaning to it, working with it, and enriching it by linking it to their own tacit knowledge, seemed an ingredient that was valid for all cases and is also reflected in other research (for example, Innes, 1998). The same seemed to apply to urgency. Only if the discussed topic was deemed sufficiently urgent, would participants act upon the lessons learned in the workshop, provided that one was organised in the first place (for example, Rouwette et al, 2002). As such, a 'theory' of how to generate informed deliberation of market-conscious planning strategies slowly emerged.

Following the full experiential cycle, however, the research did not end with a conclusion. On the basis of ideas about the mechanism through which the approach does (or does not) work, new hypotheses are generated about how the approach could be improved. For example, in order to enhance opportunities for the integration of explicit and tacit information, neighbourhoods' positions were now mapped by looking at a more tangible characteristic, that is, changing property values, instead of the indicators used before. In addition, more time was allocated for discussing the maps. However, in order to see whether this was an improvement to the approach, this had to be tested in another workshop (TNS). It turned out that the maps not only proved a more tangible piece of information (O\&R), but also, the planning department started using these new maps in other, separate projects (CE). In addition, the planning department and the university have produced a workbook for the portfolio approach, which explains to possible users when and how they can apply the approach.

\section{Reflections on the experiential research design}

As shown, in all three research projects the experiential research approach led to useful new planning concepts and processes that could be applied in planning practice, as well as debated in academia. They show that by bringing the two worlds together in the 
production of knowledge it might be easier to strike a balance between rigour and relevance, between knowledge that is on the one hand theoretically and empirically sound and on the other hand also useful for and valued by the practitioners who have to use this type of knowledge. Producing this type of knowledge requires careful consideration of where and how collaboration between practitioners and researchers takes place. It seems important to situate the phase of testing just outside of the real planning process to open up the minds of the practitioners to new ideas. There has to be room for experiments to fail. However, it also has to be linked to real planning issues practitioners want to address. The same holds true for the phase of observation and reflection. It is important to create a safe environment where practitioners feel free to criticise and reflect on the experiment and their current planning practices. If this reflection is part of the planning process itself it may lead to strategic behaviour and hamper the experiential learning process. It seems that the role of the university as the 'independent' facilitator of these projects could be an important precondition for this safe environment. It is important to be clear about the expected outcomes and the role of a researcher in such research projects. The researchers are not there to solve the problem for the practitioners, but to work with them to collectively look for new ways to deal with a particular issue. To tackle the problem of being actively involved in a particular planning process as a researcher and having to reflect at the same time, it could be useful to let members of the research team have different roles, where one can be the facilitator of the process while another observes.

However, apart from its merits the experiential case-study design requires caution when drawing scientific conclusions. In explanatory science there is always the threat of bias, through (un)consciously working towards conclusions that fit hypotheses stated beforehand. In design science however, the researcher not only tests hypotheses, but also explicitly aims at designing a tool that works in practice. He or she may therefore be tempted to defend his or her tool even when it actually does not work, or blame this failure on other aspects. Undertaking a realistic evaluation of each case using the context-intervention-mechanism-outcome framework [Van Aken (2004) adapted from Pawson and Tilley (1997)] is a way to address these issues. Carefully reviewing the outcomes of the cases and relating these outcomes to the planning interventions and the planning context, as was done in these research projects, tells you more about the underlying mechanism that produces a particular result. However, given the many interdependencies, one always has to be cautious about the causal mechanisms at play.

The questions of what can be generalised and transferred to other cases and how this can be done are essential. The type of knowledge that is produced within a case often takes the form of shared tacit knowledge between participants about how to solve a particular planning problem. This makes it difficult to transfer (explicit) outcomes between cases. However, what possibly can be transferred are procedures and methods of producing particular 'know how' to solve a planning problem in a given context.

\section{Implications for planning research}

Our argument that research in planning should adopt a more experiential case-study design has wider implications for the realm of academic research in planning. At present, most academic research in planning does not, or at least not apparently, engage in the full experiential learning cycle as described in this paper. With reference to figures 1 and 2, it most typically moves from the observation of and reflection on concrete experience to the generation of new abstract concepts, and then it stops. Only very rarely does it explicitly test these concepts in new situations (as in a pilot application) and hardly ever, or maybe never, follows up the (eventual) adaptation of concrete experience. If one were to judge from the pages of academic planning journals 
as shown above, it would seem that researchers have no role in the application of the knowledge they produce, just as practitioners have no role in its generation. As we have argued in this paper, we believe instead that opportunities for improving both practice and theory are thus lost. We do not wish to contend, however, that the dominating type of 'observational' academic planning research should not be pursued, just as we are not arguing that planning practice without an explicit link to academic research is useless. Distance between professional practice and academic research also has its distinct advantages (for example, Thomas, 2005). Besides, many planning practices are simply too complex to be 'experimented with'. Observation, reflection, and conceptualisation are in many cases the only possibility. Whether and how the approach presented in this paper can be extended to issues other than those discussed in the three examples has, therefore, to be explored. However, we believe with Dewey $(1960 ; 1964)$ and Schön (1983) that more 'participatory' research approaches, including the actual testing of new concepts and the transformation of practice, are essential to as change oriented a discipline as planning, and therefore deserve more space in academic practice and literature. On the other hand, we also believe that the involvement of planning academics should, in practice, go beyond the status of (quasi)consultancy. It should abide by the norms of scientific rigour (such as clarity on issues of validity) and preserve critical distance from practice (for example, by systematically submitting procedures and results to peer review). The aims of the methodological framework proposed in this paper are to be a contribution in precisely that direction.

Finally, the argument we have presented has implications for the way academic research is organised and funded. In the present context academic research is geared increasingly at obtaining the recognition of peers (that is, other academics, and particularly academics abroad), rather than recognition of those who are supposed to use it (planners at home). A main reason for this is that funding, but also individual and organisational prestige, are increasingly linked to that recognition, as expressed in international publications, invitations to lecture at universities abroad, and research assessments by fellow scientists. At the other end of the research-practice spectrum, room for reflection by practitioners is becoming more difficult to find within increasingly short-term output-oriented professional planning practices. This is a situation that might not be problematic in most natural and social sciences, but it certainly is in a field where research is change oriented and is also expected to support a practice. Thus, change in this situation would also require transforming the institutions determining the organisational modes, funding mechanisms, and assessment criteria of planning research. This is, or course, not going to be an easy or uncontroversial task. We believe, however, that awareness by planners and academics alike of the need for change would be an important step. In this respect, some recent debates in the academic planning community seem to point in a hopeful direction (for example, Balducci and Bertolini, 2007; Charlton, 2007; Healey, 2007). Furthermore, planning is not alone in needing to change and can learn from the experience of others. The discussion reflects more general problems shared by other profession-related disciplines, where similar concerns are being raised. Examples are as diverse as forestry (Brown, 2003), information systems (Moody, 2000), organisational psychology (Anderson et al, 2001), and management science, where there is a lively, ongoing debate on these issues (Fincham and Clark, 2009). Also, in these other disciplines more interaction between, or even integration of, the institutions and incentive structures governing academic and professional life is seen as a condition for a more productive relationship between the two. In management science, some already see a shift in this direction (Starkey et al, 2009). They cite as evidence national research programmes earmarking funds for research - practice partnerships similar to the programmes that made possible 
two of the research projects described in this paper. In the Netherlands, there seems to be a significant and growing demand from the field for this type of research, which was reflected by the eagerness of a variety of actors to participate in the projects. The extensively overlapping institutions and converging incentive structures of medical research and practice are sometime seen as exemplary and suggested as a mode to replicate (for example, Brown, 2003; Moody, 2000). However, even within medicine there is debate (for example, Roberts, 1999). Explicitly linking the discussion in this paper to these discussions and experiences in other disciplines would be a very interesting and useful follow up to the path of enquiry reported here.

Acknowledgements. All authors made an equal contribution to this paper. We wold like to thank the anonymous referees for their useful comments that helped us to improve the paper. Furthermore we would like to thank the three institutions that made possible the three research projects discussed. In the order that they appeared in the paper these are Transumo (TRANsition SUstainable MObility), Habiforum (Synergy in urban networks), and the Municipality of Amsterdam (Urban Planning department).

\section{References}

Anderson N, Herriot P, Hodgkinson G P, 2001, "The practitioner-researcher divide in industrial, work, and organizational (IWO) psychology: where are we now, and where do we go from here?" Journal of Occupational and Organizational Psychology 74391 - 411

Argyris C, Schön D A, 1989, "Participatory action research and action science compared" American Behavioral Scientist $32612-623$

Balducci A, Bertolini L, 2007, "Reflecting on practice or reflecting with practice?" Planning Theory and Practice $8532-533$

Banister D, 2005 Unsustainable Transport (Spon, London)

Baskerville R L, Wood-Harper A V, 1996, "A critical perspective on action research as a method for information systems research" Journal of Information Technology 11235 - 264

Bhat C, Handy S, Kockelman K, Mahmassani H, Chen Q, Weston L, 2000 Development of an Urban Accessibility Index: Literature Review (Center for Transportation Research, University of Texas, Austin, TX)

Brown N, 2003, "A critical review of forestry education" Bioscience Education 1-4, http://www.bioscience.heacademy.ac.uk/journal/vol1/beej-1-4.aspx

Cervero R, 2006, "Alternative approaches to modeling the travel-demand impacts of smart growth" Journal of the American Planning Association 72 285-295

Charlton S, 2007, "Mobilising knowledge resources in the global south: learning by doing and learning by thinking" Planning Theory and Practice $8383-386$

Dewey J, 1960 The Quest for Certainty (Putnam, New York)

Dewey J, 1964 Reconstruction of Philosophy (The Beacon Press, Boston, MA)

Eden C, Huxham C, 1996, "Action research for management research" British Journal of Management $775-86$

Fincham R, Clark T, 2009, "Introduction: can we bridge the rigour - relevance gap?" Journal of Management Studies $\mathbf{4 6} 510$ - 515

Flyvbjerg B, 2001 Making Social Science Matter. Why Social Inquiry Fails and How it Can Succeed Again (Cambridge University Press, Cambridge)

Friedmann J, 1973 Retracking America: A Theory of Transactive Planning (Anchor Books, Garden City, NY)

Friend J K, Hickling A, 1987 Planning Under Pressure: The Strategic Choice Approach (Pergamon Press, Oxford)

Geertman S, Stillwell J, 2008 Planning Support Systems: Best Practices and New Methods (Springer, New York)

Gerring J, 2007 Case Study Research: Principals and Practices (Cambridge University Press, New York)

Gibbons M, Limoges C, Nowotny H, Schwartzman S, Scott P, Trow M, 1994 The New Production of Knowledge: The Dynamics of Science and Research in Contemporary Societies (Sage, London)

Healey P, 2007, "European integration and the planning community: reflections on the AESOP project" Town Planning Review 75(5) iii - vii

Hoetjes P, Bertolini L, le Clercq F E, 2006, "Towards market-conscious planning in Amsterdam: a portfolio approach" Planning Practice and Research 21 179-200 
Innes J E, 1998, "Information in communicative planning" Journal of the American Planning Association $6452-63$

Innes J E, Booher D E, 2000, "Indicators for sustainable communities: a strategy building on complexity theory and distributed intelligence" Planning Theory and Practice 1173 - 186

Kolb D A, Fry R, 1975, "Toward an applied theory of experiential learning", in Theories of Group Process Ed. C Cooper (John Wiley, Chichester, Sussex) pp $33-57$

Lee D B, 1994, "Retrospective on large-scale urban models" Journal of the American Planning Association $6035-40$

Meadows D H, Robinson J M, 2002, "The electronic oracle: computer models and social decisions" System Dynamics Review 18271 - 308

Meyer M D, Miller E J, 2001 Urban Transportation Planning a Decision-oriented Approach (McGraw-Hill, Boston, MA)

Moody D L, 2000, "Building links between IS research and professional practice: improving the relevance and impact of IS research", in International Conference on Information Systems. Proceedings of the Twenty First International Conference on Information Systems. Brisbane, Queensland, Australia Eds R A Weber, B Glasson (Association for Information Systems, Atlanta, GA) pp $351-360$

Needham B, 2004, "John Friend: advising and theorizing" Planning Theory 3237 -247

Nonaka I, Takeuchi H, 1995 The Knowledge-creating Company: How Japanese Companies Create the Dynamics of Innovation (Oxford University Press, New York)

Nowotny H, Scott P, Gibbons M, 2001 Re-thinking Science: Knowledge and the Public in the Age of Uncertainty (Polity Press, Oxford)

Pawson R, Tilly N, 1997 Realistic Evaluation (Sage, London)

Polanyi M, 1967 The Tacit Dimension (Doubleday, New York)

Roberts J, 1999, "From academia to private medicine: where did the profession go?" Western Journal of Medicine $\mathbf{1 7 0} 308$

Rouwette E A J A, Vennix J A M, Van Mullekom T, 2002, "Group model building effectiveness: a review of assessment studies" System Dynamics Review 18 5-45

Schön D A, 1983 The Reflective Practitioner: How Professionals Think in Action (Basic Books, New York)

Simon H A, 1969 The Science of the Artificial (MIT Press, Cambridge, MA)

Starkey K, Hatcheul A, Tempest S, 2009, "Management research and the new logics of discovery and engagement" Journal of Management Studies 46547 - 558

Straatemeier T, Bertolini L, 2008, "Joint accessibility design: a framework developed for and with practitioners to stimulate the integration of regional land-use and transport strategies in the Netherlands" Transportation Research Record number 2077, $1-8$

Stringer E, 1999 Action Research in Action (Sage, London)

te Brömmelstroet M C G, Bertolini L, 2008, "Developing land use and transport PSS: meaningful information through a dialogue between modelers and planners" Transport Policy $15251-259$

te Brömmelstroet M C G, Schrijnen P M, 2010, "From planning support systems to mediated planning support: a structured dialogue to overcome the implementation gap" Environment and Planning B: Planning and Design $373-20$

Thomas H, 2005, "Pressures, purpose and collegiality in UK planning education" Planning Theory and Practice $6238-246$

Thompson Klein J, Grossenbacher-Mansuy W, Häberli R, Bill A, Scholz R W, Weit M, 2001 Transdisciplinarity: Joint Problem Solving Among Science, Technology and Society: An Effective Way of Managing Complexity (Birkhäuser, Basel)

Van Aken J E, 2004, "Management research based on the paradigm of the design sciences: the quest for field-tested and grounded technological rules" Journal of Management Studies 41219 - 246

Van Aken J E, 2005, "Management research as a design science: articulating research products of mode 2 knowledge production and management" British Journal of Management 16(9) 19-36

Vonk G, Geertman S, Schot P, 2005, "Bottlenecks blocking widespread usage of planning support systems" Environment and Planning A 37 909-924

Yin R K, 2003 Case Study Research: Design and Methods (Sage, Thousand Oaks, CA) 
Conditions of use. This article may be downloaded from the E\&P website for personal research by members of subscribing organisations. This PDF may not be placed on any website (or other online distribution system) without permission of the publisher. 